\title{
Discriminação de gênero e inserção de meninas na área de TI
}

\author{
Vanessa Petró, Vinicius Hartmann Ferreira, Renata Luiza Muller, Jéssica \\ Gabrieli Schmitz Hahn, Leandro von Borstel Assmann
}
Instituto Federal de Educação, Ciência e Tecnologia do Rio Grande do Sul - IFRS, Feliz, Rio Grande do Sul, Brasil

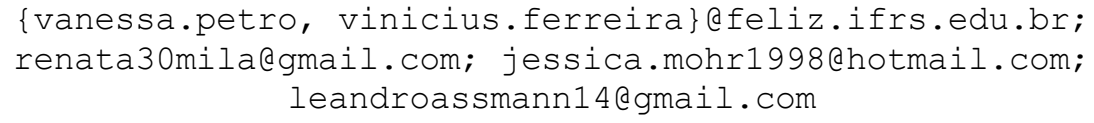

\begin{abstract}
.
The study addresses the school and professional trajectories of graduates of a Technical Course in Informatics Integrated to High School. The objective of the study is to analyze aspects that influence the formation of female professional trajectories in the IT area. The research has a qualitative approach, based on the case study method and conducted 09 narrative interviews with graduates of that Course. Understanding the trajectories is based on the conception of gender socialization processes. Among the main results found, the forms of gender prejudice in the Course stand out, even though they are almost always veiled and the forms of discrimination in the world of work.
\end{abstract}

\begin{abstract}
Resumo.
$O$ estudo aborda as trajetórias escolares e profissionais de egressas de um Curso Técnico em Informática Integrado ao Ensino Médio. O objetivo do estudo é analisar aspectos que influenciam a formação de trajetórias profissionais femininas na área de TI. A pesquisa é de abordagem qualitativa, baseado no método de estudo de caso e realizou 09 entrevistas narrativas com egressas do referido Curso. A compreensão das trajetórias é feita a partir da concepção dos processos de socialização de gênero. Entre os principais resultados encontrados destacam-se as formas de preconceito de gênero no Curso, mesmo que quase sempre velados e as formas de discriminação no mundo do trabalho.
\end{abstract}

\section{Introdução}

A desigualdade de gênero é uma questão que assola a humanidade ainda no século XXI. A promoção da igualdade entre os sexos e da autonomia das mulheres está incluída como uma das metas do milênio, estabelecidas pela Organização das Nações Unidas. Entretanto, ainda estamos muito distantes de alcançar tal meta. As mulheres já são maioria nos diferentes níveis de ensino. Mas, olhando em específico para o ensino superior, as mulheres enfrentam barreiras em áreas como as ciências exatas. As mulheres correspondem a 13,3\% das matrículas nos cursos presenciais de Computação e Tecnologias da Informação e Comunicação e 21,6\% na área de Engenharia. No outro extremo, nos cursos que envolvem a área de bem estar e cuidado, a presença feminina é de, por exemplo, $88,3 \%$ no curso de Serviço Social. No mundo do trabalho ainda são enfrentadas dificuldades tais como salários mais baixos que os homens [IBGE 2021]. 
Diante do cenário apresentado, o foco deste estudo está na análise das implicações da desigualdade de gênero em uma área específica que é a da Tecnologia da Informação (TI). Para tanto, o recorte da pesquisa que deu origem a este artigo é a análise da trajetória escolar e profissional de egressas de um Curso Técnico em Informática Integrado ao Ensino Médio, ofertado por uma instituição de ensino federal. O Curso possui estágio curricular obrigatório, então, a partir do terceiro ano os estudantes podem ter sua primeira experiência profissional na área. O objetivo geral deste estudo é analisar aspectos que influenciam a formação de trajetórias profissionais femininas na área de TI no âmbito de um curso técnico integrado. Além destes, tem-se como objetivos específicos: a) analisar a percepção de meninas sobre a inserção na área de informática e b)identificar os aspectos relacionados à questão de gênero que influenciam as trajetórias femininas na área de TI. Por meio de uma abordagem qualitativa, foi desenvolvido um estudo de caso do referido Curso, realizando-se a coleta de dados por meio de nove entrevistas narrativas, posteriormente, analisadas pela técnica de análise de conteúdo. A pesquisa ainda está em andamento e o número de entrevistas está sendo ampliado. A análise das entrevistas foi ancorada na revisão da literatura sobre o tema, além dos estudos sobre socialização e gênero.

Os principais resultados indicam que o momento da realização do estágio curricular obrigatório é um marco importante na trajetória das meninas, sobretudo em relação à percepção sobre formas de discrimação de gênero. Nos locais onde realizam os estágios vivenciam situações que reproduzem estereótipos de gênero, possuem suas capacidades questionadas algumas vezes, além de terem poucos exemplos de profissionais femininas. No que se refere ao Curso, as egressas possuem dificuldades de reconhecer formas de discriminação de gênero, embora relatem situações dessa natureza, principalmete advindas dos colegas.

Além da introdução, o artigo é composto por uma seção que trata sobre os aspectos metodológicos. A terceira seção apresenta a revisão da literatura sobre o tema e, na quarta, são apresentados e analisados os resultados encontrados nas entrevistas. Por fim, são apresentadas as considerações finais.

\section{Procedimentos metodológicos}

A pesquisa é de abordagem qualitativa, o que privilegia a coleta de informações de modo aprofundado, com uma visão interior do grupo pesquisado, observando vários elementos de modo simultâneo em um pequeno grupo [Victora, Knauth e Hassen 2010]. A pesquisa qualitativa não tem objetivos como os de surveys, não se apresenta como generalizável, nem elabora perfis mais comuns entre estudantes, com caráter estatístico. Esta pesquisa busca identificar como as entrevistadas elaboram suas narrativas e tematizam a relação entre os condicionantes destacados em suas trajetórias.

O método de estudo de caso, por sua vez, permite investigar uma situação contemporânea em profundidade, considerando diferentes pontos de partida para o acesso às fontes de evidência, principalmente, aspectos contextuais, além de permitir a combinação de técnicas para a coleta de dados a fim de se alcançar os objetivos [Yin 2010].

A técnica utilizada para a coleta de dados foi a entrevista narrativa. A entrevista narrativa busca compreender os contextos onde as biografias foram construídas [Weller 2009]. A utilização desse tipo de técnica de pesquisa apresenta vantagens em relação a outros formatos que são arbitrários ao isolar as trajetórias biográficas dos eventos sociais a que estão atreladas. Assim, procura-se, através das narrativas, a forma como as ações 
são projetadas, realizadas e também retomadas pelos indivíduos, além de possibilitar a motivação para as ações. Parte-se da ideia de que cada indivíduo coloca-se na vida de uma maneira específica, o que é denominado de "situação biográfica" [Natanson 1974].

Até o início do ano de 2020, seis turmas concluíram o curso, compreendendo um total de 149 estudantes, dentre as quais, 42 eram meninas. Das 42 meninas que concluíram o curso, cinco seguiram trabalhando e/ou estudando na área de informática.

Para a realização das entrevistas com egressas o trabalho partiu de uma listagem fornecida pelo setor de estágio da instituição com a indicação de todos os estudantes que haviam realizado o estágio curricular obrigatório. O estágio é obrigatório, então essa listagem corresponde a todos os estudantes que concluíram o curso. Partindo dessa listagem, iniciou-se um trabalho de localização das egressas para realização das entrevistas. Tal contato foi feito por meio da busca em redes sociais. Entre os primeiros critérios utilizados para seleção das entrevistadas foi a variedade de ano de ingresso no curso, as áreas de realização de estágio e ter seguido ou não na área, visando à diversidade das trajetórias contempladas. As entrevistas foram realizadas com a utilização do google meet com duração aproximada de uma hora cada. Ressalta-se que a coleta de dados ainda está em andamento e o número de entrevistadas será ampliado, somando até o momento 09 entrevistas. A pesquisa observa os cuidados éticos e as entrevistadas assinaram o Termo de Consentimento Livre e Esclarecido.

As entrevistas passaram por uma primeira análise, a qual permitiu a organização das informações em uma planilha de acordo com as categorias estabelecidas para a análise, sendo elas: representatividade feminina, papéis de gênero, estereótipos de gênero, questionamento da capacidade e assédio. Ao analisar as informações contidas nas 09 entrevistas realizadas, o estudo possui a capacidade de apreender e de elaborar oposições e paralelismos entre diferentes perfis de estudantes egressas no que se refere aos seus contextos e percursos na área de TI.

\section{Revisão bibliográfica}

O enfoque ora apresentado está em como a socialização de gênero incide sobre as trajetórias escolares e profissionais em um curso de TI. Olhar para a questão de gênero ao analisar a trajetória das entrevistadas, significa nesta análise, destacar aspectos como a percepção delas em relação à representatividade no curso e no mundo do trabalho, bem como formas de discriminação de gênero.

A concepção de gênero presente neste estudo está relacionada a uma compreensão que se distancia dos aspectos biológicos, voltando-se para a construção histórica de papéis sociais [Scott 1995]. Além disso, o conceito é pensado a partir das relações de poder que estão contidas nele e que, historicamente, indicaram formas de silenciamento, opressão e desigualdade [Louro 2014], tendo como base aqui o poder como uma estratégia.

Ao abordar a questão de gênero, trata-se também do processo de socialização, sobretudo em relação à construção dos papéis de gênero. A socialização é o processo através do qual o mundo social molda os indivíduos, isto é, transforma-os de seres biológicos em seres sociais adaptados a um contexto sócio-histórico específico [Lahire 2015]. Os traços dos indivíduos não têm origem unicamente em si, mas são fruto do relacionamento entre o próprio indivíduo e alguma outra coisa ou pessoa. As disposições sociais e os esquemas de ação são ativados conforme o contexto e são relacionais. Portanto, as disposições não podem ser tomadas como algo universal. É tendo em vista os 
vínculos estabelecidos pelos indivíduos, os lugares circulados $\mathrm{e}$ as atividades desenvolvidas que as disposições sofrem diferentes influências [Lahire 2004].

A construção dos papéis de gênero constitui-se por disposições incorporadas por meio do processo de socialização. Para o objeto de estudo aqui em análise, a forma como ocorre a relação entre homens e mulheres no campo da TI e o lugar ocupado por cada um deles é marcado por esse processo, portanto possui uma origem cultural, o que pode ser identificado ao retomar-se a trajetória das mulheres na ciência e na tecnologia.

A reduzida participação das mulheres na Ciência, Tecnologia, Engenharia e Matemática (STEM) é uma questão identificada em diferentes partes do mundo, conforme evidenciado por variados estudos. São inúmeros os fatores que marcam o cenário descrito. Um estudo para determinar a motivação de mulheres a cursar a área de STEM em universidades do México aponta que família, antecedentes culturais e aspirações particulares estão entre os motivos, possibilidades profissionais e gosto pela matemática [Oliveros-Ruiz 2019]. Entre as razões da subrepresentação das mulheres na área STEM, entre elas estão: falta de preparação científica dos professores; má atitude das mulheres em relação à ciência como consequência de falta de experiências positivas desde a infância; currículos irrelevantes para as mulheres; pedagogia do ensino de ciências em favor de estudantes do sexo masculino; "ambientes frios" para as mulheres nas aulas de ciências; pressão cultural sobre as mulheres para se ajustarem aos papeis tradicionais de gênero e uma visão inerente do mundo masculino na epistemologia científica [Cheryan et al 2017]; questionamento da capacidade das mulheres para a execução das tarefas [Aires 2018] e ausência de modelos femininos a serem seguidos nas áreas de ciências e engenharia [Cheryan et al 2017, Saavedra, 2009]. Entre os motivos relatados, mas aparecendo com menor frequência, ainda está a desigualdade salarial [Aires 2018].

Estudos sobre a participação das meninas e mulheres nos cursos de informática afirmam que elas enfrentam dificuldades. Entre esses estudos identifica-se que as meninas não relatam preconceito, mas uma análise mais aprofundada permite perceber que isso ocorre, por exemplo, professores preferem as meninas em relação aos meninos e também os colegas homens colocam em dúvida a permanência das mulheres no curso [Oliveira et al 2017]. Além disso, o fato de serem minoria nas turmas, coloca-as em evidência e, por outro lado, as discussões sobre gênero na área são muito restritas [Mochetti et al 2016]. A área de informática se constituiu por meio de valores masculinos [Castro 2013], sendo ele, muitas vezes, machista e até humilhante para pessoas do sexo feminino [Saboya 2009].

Conforme indicado, entre os motivos apontados para a resistência de mulheres em ingressar na área de TI, muitos estão relacionados à questão de gênero, o que remete a um aspecto cultural da forma como se constituem os papéis de gênero em uma sociedade patriarcal e, em específico, como isso se reflete no campo da informática. Neste contexto, há estereótipos de gênero que são perpetuados, tais como a ideia de que as mulheres devem ser responsabilizadas pelas funções de cuidado e educação, enquanto os homens deveriam estar voltados para áreas exatas, inclusive pela crença na habilidade masculina para o raciocínio lógico e cálculos.

A seguir serão apresentadas e analisadas as percepções das egressas sobre suas experiências na área de TI, principalmente a partir dos estágios realizados.

\section{Apresentação e discussão dos resultados}


Nesta seção será apresentada a análise das nove entrevistas realizadas com as egressas do curso objeto deste estudo. Com a finalidade de manter preservada a identidade das entrevistadas, são utilizados nomes fictícios. O texto está organizado seguindo as categorias utilizadas para a análise: representatividade feminina, papéis de gênero, estereótipos de gênero, questionamento da capacidade e assédio.

No que se refere aos resultados encontrados, descatam-se os seguintes: a) os preconceitos evidenciados em relação às meninas, mesmo que, por vezes, de forma velada, no curso e b) as formas de discriminação no mundo do trabalho, lidas aqui sob o recorte das suas experiências durante a realização do estágio curricular obrigatório.

Uma das questões levantadas pelas entrevistadas é a falta de representatividade feminina no curso. Isso ocorre de três formas, sendo: os poucos exemplos de mulheres na área de tecnologia apresentados, sobretudo na área da história da computação; o reduzido número de docentes mulheres e o baixo número de matrículas de meninas no curso. $\mathrm{O}$ trecho da entrevista de Ada reflete essa questão.

"[...] u única professora que a gente tinha na parte técnica foi a (omitido) né. Então, isso talvez já começa em questão das pessoas ou das mulheres procurar se desenvolver nessa área e trabalhar nessa área também. Então, eu vejo que, por exemplo, ali na empresa também, que na parte mais assim de suporte, na parte que tu precisa de graduação ou algum curso superior nessa área, se tu for analisar o número de meninas que tem, comparado com o número de meninos é bem diferente, sabe?!" (Ada)

A percepção de Ada reflete o processo de socialização nos papéis de gênero. O fato de ter ou não exemplo de trajetórias femininas na área de TI ajuda a construir uma ideia do que compete ou não às mulheres fazerem. Isso faz parte de um conjunto de disposições que vai sendo incorporado e que constitui uma visão sobre aquilo que a mulher pode ser [Lahire 2004]. Obviamente, isso não se apresenta como uma sentença que jamais poderá ser revertida, afinal os processos de socialização são múltiplos e podem ser reconstruídos [Lahire 2004].

Um dos reflexos da falta de representatividade feminina é evidenciado por Dorothy, ao afirmar que não se sentia confortável no espaço da sala de aula, além de não conseguir acreditar na viabilidade da carreira em decorrência da falta de exemplos.

"Eu acredito que sim, que não tanto por, bem isso que tu falou, se identificar, que fazia falta assim, porque não adianta, a gente não se sentia como tendo lugar, a gente não tinha como ver que aquilo ia dar um futuro sabe, que a gente não tinha muitos exemplos de que aquilo daria futuro." (Dorothy)

O fato de Dorothy expressar que não havia espaço na sala de aula para se sentir parte da turma é uma das formas de manifestação de discriminação de gênero. Entretanto, esse não é um tema fácil de ser abordado pelas entrevistadas, quando o objeto de análise é o próprio curso ${ }^{1}$. Comumente, quando questionadas sobre preconceitos em aula ou formas de discriminação, as egressas falam que não sofreram nenhum tipo de desrespeito durante seu tempo na instituição. Mas, mesmo não admitindo a situação, mencionam inúmeros fatos que evidenciam a discriminação de gênero, sinalizando o quanto isso é naturalizado nas práticas cotidianas e se perpetua. Mary indica que no momento em que fazia o curso não tinha maturidade para perceber essas situações.

"Sinceramente naquela época minha cabeça não sabia muita diferença, vamos dizer assim. [...] Daí fiquei pensando: 'cara, a minha cabeça anos atrás não saberia dizer: " Não, os dois gêneros, eles são falados certinho. Não, capaz" '. Mas não é, tem essa divisão. Assim, naquela época eu não sei, agora lembrar eu não lembro." (Mary)

\footnotetext{
${ }^{1}$ Há hipótese de que isso pode ocorrer porque a entrevistadora é professora do curso ou também em decorrência do fato delas terem uma admiração grande pela instituição e pelos efeitos que a passagem por ela teve nas suas vidas.
} 
Uma das formas de discriminação de gênero é expressa pela narrativa de Ruth, que aponta para uma situação em que meninos e meninas possuem papéis a serem desempenhados, havendo, assim, certa cumplicidade na forma como ambos agem. Ela deixa claro que, na sua perspectiva, os meninos possuíam mais conhecimento sobre a área de informática do que as meninas, enquanto que as meninas eram vistas como mais habilidosas em outras disciplinas ou tarefas, tais como escrever. Assim, muitas vezes de forma tácita, cada um(a) desempenhava seu papel de forma harmônica, na sua visão. Mesmo que Ruth tenha a preocupação de utilizar esse comportamento para afirmar a inexistência de discriminação, ele evidencia a reprodução de estereótipos sobre o papel de meninos e meninas na sala de aula [Carvalho 2001]. Inúmeras vezes, em diferentes entrevistas, as egressas afirmam que os meninos possuem mais facilidade nas disciplinas técnicas em relação às meninas, o que mais uma vez mostra a reprodução de um estereótipo.

"Não, porque mesmo que eles sabiam muito eles também não estudavam tanto, então tipo assim, coisas de... trabalhos que demandavam mais tempo dai pra escrever ou algo assim, eles gostavam de fazer com a gente porque a gente fazia toda essa parte e eles faziam mais a parte lógica sabe? [...] Então, era uma relação que tipo, não... tipo eles sabiam que sabiam mais, mas eles também sabiam que precisavam da gente pra fazer uma parte assim. Mas, era bem... não, não era tipo, não tinha um Bullying." (Ruth)

Adele ainda complementa essa visão afirmando que as meninas tinham um desempenho melhor nas áreas de linguagens e humanas e os meninas nas exatas e disciplinas técnicas. Sendo assim, a formação de grupos compostos funcionava como uma troca, já que estava tacitamente estabelecido que cada um destes se responsabilizaria por assumir o protagonismo em cada uma das áreas no momento da realização das tarefas.

Tal arranjo apontado por Adele coloca em evidência uma questão muito delicada que é a condução da formação de grupos para o desenvolvimento dos trabalhos em sala de aula. Se, por um lado, segregar meninos e meninas pode apresentar um problema sério até mesmo por potencializar disputas e comparações, por outro, pode negligenciar a necessidade de alunos e alunas buscarem desenvolver suas potencialidades em todas as áreas. Uma alternativa parece ser o desenvolvimento do protagonismo de meninos e meninas nas diferentes áreas do conhecimento, encorajando-os a desenvolverem qualquer tarefa. Além de buscar romper com estereótipos que sustentam esses comportamentos.

"Não, não exatamente por isso, não pelos guris dizer 'ah, elas não sabem', mas tu via que sempre criava tipo grupinho. Se era em duplas ou trios, era sempre dois guris e uma guria, porque se a gente precisava fazer a documentação, a gente fazia e os guris programavam, dai para gente era mais fácil escrever, fazer todo relatório, a gente fazia e eles programavam..." (Adele)

Esse tipo de percepção das meninas aponta também no sentido delas incorporarem a crença de que possuem poucas habilidades para a aprendizagem dos conteúdos técnicos, conforme descreve Grace.

"Eu me comparava bastante aos meus colegas guris porque eles sempre parecem muito melhores nas matérias técnicas e eu acabava me rebaixando muito a isso, não me achava capaz de fazer as matérias do ensino médio mas acho que isso foi o principal motivo na dificuldade" (Grace)

Ainda falando de preconceito e estereótipos em sala de aula, Edith chama atenção para um tipo de comportamento oriundo dos meninos que ela classifica como "piada", que embora reflita uma forma de preconceito, ela afirma que as meninas ignoram para não perderem os amigos e não serem taxadas de "reclamonas". Elas se convencem que são só piadas e que não significam nada além disso, mesmo causando desconforto.

"[...] só com os colegas eles iriam tirar sabe tipo 'ai, não sabe' 'a menina não sabe ainda muita coisa', mas vindo dos professores não, mas dos colegas sim até as vezes eles faziam piadinhas como 'vai lavar a louça' mas eu sempre levei na piada." (Edith) 
No ambiente de realização do estágio curricular obrigatório a percepção é oposta daquela apresentada quando o recorte é o curso e a instituição de ensino são muitos os relatos sobre situações discriminatórias. Trata-se aqui neste artigo sobre as experiências das meninas no momento de realização dos estágios que se constituem como um marco importante para a formação das mesmas e, em alguns casos, a única experiência de trabalho na área de TI. Das 42 meninas que realizaram estágios entre os anos 2013 e março de 2020, podemos dividir essas experiências em áreas, tais como: ensino, desenvolvimento, manutenção e suporte, sendo que a maioria delas concentra-se nas duas últimas áreas ${ }^{2}$.

A primeira dificuldade encontrada pelas meninas para realizar o estágio já pode ser identificada no momento da escolha do local, pois algumas empresas indicam preferência pelos meninos. Essa situação foi enfrentada por Mary e suas colegas ao buscarem vagas em determinada empresa.

"Não, a gente tem um monte de vaga, não sei o quê. Daí tá, beleza, a turma inteira eu acho que mandou [currículo], pelo menos os que eu tinha contato mandaram lá currículo. E daí depois: "Não, a gente não tem vaga. Não tem vaga. Depois a gente descobriu, eles anunciaram que tavam contratando, só que homens que tinham carteira [de motorista], que não sei que, não sei que." (Mary)

Sobre os locais de estágio, percebe-se que os meninos tinham uma tendência maior em fazer seus estágios em setores de manutenção, suporte e desenvolvimento, já, entre as meninas, era comum algumas fazerem em escolas ou cursos de informática. Ruth afirma que essa escolha foi pelo grau de facilidade de executar o estágio em um curso de informática, principalmente porque ela já estava decidida a não seguir na área.

[...] Eu acabei optando pelo mais fácil, porque eu já tava meio que decidida a fazer outro curso igual depois que eu saísse dali, sabe?! [...] Não demandava, assim ter muito conhecimento, assim de coisas muito aprofundada de tipo programação, hardware e software, já é bem mais [...] (Ruth)

Em profissões marcadamente masculinas é comum que sejam criados nichos para a atuação das mulheres. Assim, as mulheres atuariam em determinados segmentos e isso seria justificado por supostas qualidades femininas necessárias e que faltariam aos homens, fazendo-se uso de uma abordagem que naturaliza características socialmente construídas. No caso da informática os homens estariam mais concentrados na área da programação e as mulheres na de análise de sistemas. Tal perspectiva ainda está associada à dificuldade de mobilidade das mulheres na carreira, que também foi evidenciada nas narrativas [Castro 2013].

Embora exista alguma diferenciação sobre a realização dos estágios, conforme o gênero, o mais comum é que meninos e meninas tenham a possibilidade de fazer seus estágios nos mesmos locais, o que, obviamente, não significa que o modo como serão tratados seja o mesmo. São frequentes relatos como os de Antonelli sobre a postura de chefes e de colegas que duvidam de suas capacidades ou ainda se apropriam de suas ideias.

"Quando eu fui pra outra empresa então, eu sentia eventualmente um machismo... Não era assim, chegava e falava, tu é burra, sabe?! Não era isso! Era mais ou menos assim: explicavam coisas óbvias, me explicavam... Faziam desenhos pra mim, como se eu fosse uma burra, sabe?! Algumas vezes pegavam e desenhavam um caminhão pra mim e me falaram assim: "Esse é o caminhão que vai...". (Antonelli)

Esse tipo de postura que questiona as capacidades das meninas é também reproduzido pelos clientes das empresas, conforme o relato de Grace. O aspecto que Grace aponta é que ela, sendo a única mulher do setor onde trabalha, acaba sendo vítima de inúmeros equívocos e preconceitos. Tais acontecimentos mostram como a falta de

\footnotetext{
${ }^{2}$ Mais informações sobre esse aspecto podem ser conferidas no artigo [oculto para avaliação]
} 
diversidade em um ambiente de trabalho pode afetar o conjunto das relações, quando recebem uma pessoa que não é esperada.

"Então, era tudo complicado demais, todo mundo não entendia ou alguns me ajudavam, outros ficavam encarando com cara fechada ou os clientes ligavam e desligavam porque achavam que eu era secretária, ou achavam que eu era a ouvidoria da empresa e começavam a xingar e reclamar de tudo, era terrivel. No início foi bem complicado, então, até todo mundo começar a se acostumar com a ideia de ter uma mulher lá dentro do suporte." (Grace)

Adele foi convidada a integrar o grupo de desenvolvedores da empresa e relata a situação de desconforto em relação à dinâmica de funcionamento da empresa que acabava por expor as dificuldades de cada integrante.

"E eu era a única guria, mulher, na parte de programação, era bem estranho assim. Não era muito, não foi nem um pouco receptivo, e eu lembro que me sentia bem mal quando a gente tinha que fazer todas as segundas uma reunião, de pé assim, uma rodinha para falar assim... o que cada um tinha feito e eu me sentia estranha e assim não... como eu tinha dificuldade na linguagem, eu não conseguia fazer muita coisa, dai eu já não tava produzindo. 360 horas [de estágio]... Eu lembro que eu quase contava que nem palitinho no caderno pra acabar meu estágio, eu acho que fiquei nem uma semana a mais e já pedi pra sair" (Adele)

Katherine relata como o tratamento dispensado a ela e às outras colegas era diferente em relação aos homens. Katherine reforça que mesmo as mulheres tendo especialização na área, muitos homens achavam que possuíam mais conhecimentos que elas, mesmo não tendo cursos na área.

"Não só no IF, mas na (empresa de manutenção) eu via que o público era muito mais masculino e os profissionais que não tinham cursos específicos, comparado com mulheres que tinham cursos especificos, se achavam mais qualificados do que as mulheres com curso." (Katherine)

A situação descrita por Katherine se reflete na possibilidade de progressão na carreira dentro da empresa, conforme aponta Dorothy.

O teleatendimento lá é todo... 80\% mulher, sabe?! E as oportunidades lá, avançar de nível, ir para um cargo maior é ao contrário, 90 \% homens. Então, tinha essa dificuldade de evoluir, sabe?! Me via presa num cargo, num cargo baixo, sabe?! Por mais que eu tivesse já terminando meu curso, eu não ia conseguir evoluir. Sabe eu não ia conseguir um cargo maior, mesmo tendo um conhecimento maior, uma formação maior, sabe?! E a principal dificuldade de lá era essa, conseguir crescer, conseguir sair do lugar sabe, mesmo se formando. (Dorothy)

O que Dorothy afirma está em consonância ao que apresentam os estudos sobre o mundo do trabalho. Aproximadamente $70 \%$ da força de trabalho nos call centers é feminina e $45 \%$ de jovens entre 18 e 25 anos [Nogueira 2009], o que reflete também a precarização do trabalho feminino.

As egressas relataram que, mesmo não querendo, acabavam incorporando o estereótipo de que meninas eram melhores fazendo atividades administrativas e de escrita, e que os homens faziam a parte de programação. Além desse comportamento ser muito frequente no ambiente do curso, conforme já foi descrito, também se reproduzia no ambiente de trabalho.

"[...] sempre chamado da parte administrativa vai pras gurias e os chamados técnicos vai pros guris. Sempre é assim, não tem muito como fugir disso. E desde que eu entrei também todos os chamados administrativos eram passados para mim, o que antes era feito por homens [...] "(Grace)

Outro tema que emergiu das entrevistas foi o assédio moral e sexual. Entretanto, as entrevistadas apenas denominaram desse modo quando se tratou, da forma como ela classifica, de assédio sexual.

"Eu tive que ouvir de várias pessoas de nossa olha "bendita entre os homens" e foram questões assim mais do cotidiano em relação ao assédio mesmo, eu tive que deixar de usar legging, por exemplo, pra não ser assediada na cara dura em uma das empresas por um dos meus chefes. (Antonelli) 
A construção social que vincula tecnologia e masculinidade é o principal fator motivador do desinteresse das mulheres pelo setor de TI [Castro 2013]. Isso está vinculado ao preconceito sofrido pelas mulheres quando intentam uma carreira nessa área, passando por situação de assédio moral, sobretudo quando seus colegas dúvidam das suas capacidades, conforme já sinalizado pelas narrativas das entrevistadas e também assédio sexual, conforme a narrativa de Antonelli.

Por fim, cabe destacar como as egressas naturalizam as situações de discriminação nos locais de estágio. Quando questionadas se em algum momento elas reportaram aos superiores os episódios ocorridos, são unânimes em afirmar que não acreditavam na possibilidade de alguma mudança de atitude por parte das empresas. Em algumas situações consideradas mais graves como a enfrentada por Antonelli havia uma conversa com a professora orientadora do estágio, especialmente por ela ser uma mulher. Aos professores homens essas situações não eram reportadas. Entretanto, essa conversa assumia mais um caráter de desabafo, pois havendo a descrença em mudanças isso não chegava a ser discutido com as empresas e nem mesmo pela própria instituição de ensino com a coordenação do curso ou o setor de estágios.

\section{Considerações finais}

As experiências relatadas pelas meninas na área de TI são marcadas pelos processos de socialização de gênero e pelas relações de poder que definem uma sociedade patriarcal e as microrrelações no seu interior. A questão da representatividade feminina, os papéis de gênero atribuídos e assumidos, os estereótipos de gênero, as descrenças nas suas capacidades e até mesmo formas de assédio marcam as trajetórias femininas. Para muitas entrevistadas a experiência no estágio trouxe muitos resultados em relação ao aprendizado, mas, ao mesmo tempo, nem todos os locais de trabalho eram os mais propícios a elas. As experiências vivenciadas atuam no sentido de não ajudar a construir um interesse em seguir na profissão. É claro que, por vezes, mesmo enfrentando as situações descritas as meninas optam por seguir a profissão (mesmo que em número muito reduzido, cerca de 5 das 42 concluintes), o que expressa a multiplicidade dos processos de socialização.

Os resultados da pesquisa sinalizam para a importância de a própria instituição de ensino atentar para esses aspectos, o que a observação empírica indica ainda ser pouco expressivo, sobretudo desnaturalizando as formas de descriminação de gênero. Nesse sentido iniciativas como o Programa Meninas Digitais, promovido pela Sociedade Brasileira de Computação, podem ter um papel importante. No âmbito do Curso, muito recentemente, foi iniciado o projeto Meninas High-Tech que está promovendo uma discussão sobre o tema.

Embora aqui já tenham sido apresentados dados relevantes sobre a questão propostas, é necessário ainda um aprofundamento na coleta e análise dos dados e também o desvelamento dos fatores que fazem com que algumas meninas prossigam na área, mesmo que tenham enfrentado situações de discriminação de gênero.

\section{Referências}

Aires, J., Mattos, G., Oliveira, C., Brito, A., Aragão, A. F., Alves, S., Coelho, T. e Moreira, G. (2018) "Barreiras que Impedem a Opção das Meninas pelas Ciências Exatas e Computação: Percepção de Alunas do Ensino Médio." In: Anais do $12^{\circ}$ Women in Information Technology (WIT2018). SBC, 2018. 
Carvalho, M. P. de. (2001) Mau aluno, boa aluna?: como as professoras avaliam meninos e meninas. Revista Estudos Feministas, 9(2), 554-574. https://doi.org/10.1590/S0104-026X2001000200013

Castro, B. (2013) "Os gargalos para o ingresso e a permanência das mulheres no mercado de TI no Brasil”, In: XII Conferencia Regional sobre la Mujer de La America Latina y Caribe.

Cheryan, S., Ziegler, S. A., Montoya, A. K.e Jiang, L. (2017) Why are some STEM fields more gender balanced than others? Psychological Bulletin, 143(1), 1-35. https://doi.org/10.1037/bul0000052

IBGE. Instituto Brasileiro de Geografia e Estatística. (2021) "Estatísticas de gênero: indicadores sociais de mulheres no Brasil", https://www.ibge.gov.br/estatisticas/multidominio/genero/20163-estatisticas-de-genero -indicadores-sociais-das-mulheres-no-brasil.html? $=\& \mathrm{t}=$ publicacoes

Lahire, B. (2015) A fabricação social dos indivíduos: quadros, modalidades, tempos e efeitos de socialização. Educação e Pesquisa, São Paulo, v. 41, n. especial, p. 1393-1404, dez.

Lahire, B. (2004) Retratos sociológicos: disposições e variações individuais. Porto Alegre: Artmed.

Louro, G. L. (2014) Gênero, sexualidade e educação: uma perspectiva pós-estruturalista. Petrópolis: Vozes.

Mochetti, K., Salgado, L., Zerbinato, A. V., Souza, B. L. e Avelino, M. R. E. (2016) "Ciência da Computação também é coisa de menina" In: Anais do $10^{\circ}$ Women in Information Technology (WIT2016). SBC, 2016.

Natanson, M.. (1974) Introducción. In: Schutz, A. El problema de la realidad social. Buenos Aires: Amorrortu, p. 11-32.

Oliveira, B. C. de, Boscarioli, C., Pereira, E. N., Souza, G. M. e Torres, L. (2017) "Egressas de Ciência da Computação da Universidade Estadual do Oeste do Paraná: o que veio depois?" In: Anais do $11^{\circ}$ Women In Information Technology (WIT2017), SBC, 2017.

Oliveros-Ruiz, M. A. (2019). STEAM as a tool to encourage engineering studies. Revista científica, (35), 158-166. https://dx.doi.org/10.14483/23448350.14526

Saavedra, L. (2009) Assimetrias de Género nas Escolhas Vocacionais In: Guião de educação - Género e cidadania, Lisboa, CIG.

Saboya, M. C. L. (2009). Alunas de engenharia elétrica e ciência da computação: estudar, inventar, resistir. PhD thesis, Universidade de São Paulo.

Scott, J. (1995) Gênero: uma categoria útil para a análise histórica. Educação \& Realidade, Porto Alegre, v. 20, n.2, jul./dez.

Victora, C. G., Knauth, D. R. e Hassen, M. N. (2010) Pesquisa qualitativa em saúde: uma introdução ao tema. Porto Alegre: tomo editorial.

Weller, W. (2009) "Tradições hermenêuticas e interacionistas na pesquisa qualitativa: a análise das narrativas segundo Fritz Schütze". In: Reunião Anual da Anped, 32, Caxambu, MG. Anais... Caxambu, MG: ANPeD, 2009. p. 1-16.

Yin, R. K. (2010) Estudo de caso: planejamento e métodos. Porto Alegre: Bookman. 